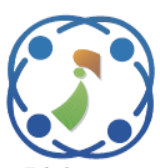

\title{
A Real Time Monitoring System for Yoga Practitioners
}

\author{
Prasanna Mani ${ }^{1 *}$, Arunkumar Thangavelu², Akshat Sharma², Nikhil Chaudhari ${ }^{2}$ \\ ${ }^{I}$ School of Information Technology and Engineering, VIT University, Vellore, India \\ ${ }^{2}$ School of Computer Science and Engineering, VIT University, Vellore, India \\ * Corresponding author's Email: prasanna.m@vit.ac.in
}

\begin{abstract}
Now a days a majority share of people undergoes through some health problems or mental stress. The reason for both may be many factors like unhealthy food habits, lack of doing body exercise, pressure from family and job environment etc. These factors can physically and mentally deteriorate the creativity and productivity of a person. Yoga can be considered as one of the finest solutions in this case though it refreshes both physically and mentally. Yoga transforms a person balanced with mental, physical and spiritual elements in the right composition. In this technology era, it will be good to integrate yoga with the trends of technology. This work proposes a scheme of integrating and monitoring yoga activities using the concept of Internet of Things (IoT) and a smart application. The body sensors (Pressure, temperature, humidity) attached with the person doing yoga senses relevant data and is processed using a central processor (Smart phone or smart devices) to provide necessary suggestions or feedbacks to the user. This work will provide a platform to the yoga practice person to monitor and review their yoga activities by themselves. Our research results claims that the various parameters like blood pressure, temperature and heart beat rate is improvised a lot after practicing yoga. Our survey results with the yoga persons doing this IoT based yoga system shows that our system is much helpful for the yoga persons to practice yoga efficiently and effectively.
\end{abstract}

Keywords: Real time monitoring, Yoga, Meditation, IoT.

\section{Introduction}

Yoga is an ancient practice of mental, physical and spiritual exercise. Various clinical studies proved that practicing yoga can reduce health risks and can be utilized for psychological healing process. About $75 \%$ of investment in healthcare is spent on lifestyle related chronic conditions like cardiovascular diseases, type 2 diabetes, obesity and cancer.[1] The solution to these conditions are simple, but the implementation takes a bit of determination and motivation. With little persistent efforts, over the course of several months, can help the human body fight and even develop the immunity against these lifestyle related medical conditions.

Yoga has shown promising results in fighting against many conditions including metabolic syndrome, diabetes and cardiovascular diseases. [2][3][4] Yoga is very different from gym and athletics. Activities like gym depend on pushing the body to the limits and bearing more and more stress. This stress is benign for very young adults, but the lifestyle followed by adults and middle-aged people asks for more focus on work. This leaves them paying less attention to their health and the effects starts to show up later. Yoga stress on balance of mind, body and spirits. The postures are not very hard for people whose age ranges between 25 and 45. Adding to that, Yoga has many alternative exercises. A fit body can be achieved by home practised yoga rather than mild athletics (running, jogging) and mild gym exercises. Yoga provides a much softer way to keep the human body in check and prevent many diseases.

Studies [5,6] have tried to determine the effectiveness of yoga practices against diseases like cancer, schizophrenia, asthma and heart diseases. It has been scientifically concluded by Sovova [7] that despite low energy expenditure, yoga practices are better in some cardiorespiratory fitness parameters 
than other aerobic activities recommended by current guidelines for Cardiovascular Diseases prevention. Other studies have provided evidence of positive effect on individuals practicing yoga regularly in factors like weight maintenance [8], BMI $[9,10]$ and $\operatorname{diet}[10]$. Yoga increases feeling of wellness, positive attitude, energy levels, memory attention, concentration, social skills, self acceptance, flexibility and strength. It reduces anxiety \& stree, depression \& tension, sugar \& cholesterol levels, hyperthyroidism, weight, blood pressures, arthritis and so on.

In this paper, we are proposing an Android app that is connected with hardware kit is highly beneficial to monitor the blood pressure level, heartbeat level ,body temperature of yoga doers. The collected data are stored in the repository and weekly reports, monthly reports could be generated through our Android App. The yoga doers can monitor the health status consistently through our Android App. Based on the report, with the guidance of yoga master, they could alter the yoga asanas to reach the normal level of Blood pressure, heartbeat rate and body temperature. The Android App also gives yoga asana directions for novice and experts and is easy to use.

The remaining part of this paper comprises of various sections like Literature survey, Proposed system architecture, System analysis and results and Conclusions. The various existing works done in this area so far is discussed in Literature review section. System architecture and design methodology is discussed in section 3. System analysis and observed results are provided in section 4 and finally our derived conclusions are provided in last section.

\section{Literature survey}

Cramer et al [11] concluded that yoga is safe and effective intervention for reducing waist circumference and systolic blood pressure in patients with metabolic syndrome who are not sticking to normal exercise routines. A lot of study has been done on effects of yoga on human body and comparison of yoga with other alternatives. More research studies has been conducted to measure the benign effects of yoga on patients with disorder, ailments and diseases.

The use of technology to enhance user's yoga experience is not new. In 2001, Gauthier et al. described a system to enhance yoga using gesture recognition [16]. The main aim was to provide practitioner with olfactory, auditory and visual stimuli which will heighten the therapeutic qualities of yoga. .Several efforts using systems like Biomuse [17] and Manjushri Mandala [20] have worked closely with technology to aid ancient practice of Yoga. Biomuse uses the neural outputs as raw data for the system. Other interactive technologies which include Virtual Baton [19] and Iamascope [18]. On the other hand, systems like Manjushri Mandala system are non-interactive yoga enhancing system. Similarly, several traditional and non-traditional input devices have been used to collect data from practitioners.

Assistance using resting pads, handles and mat has been patented by Millsap [21]. Depending on the asanas, the apparatus can have either one or more resting pads and handles. The user is required to rest his hands, feets, arms, lower back on the resting pads which gives reference points for performing yoga. The main disadvantage in this case is changing the height and positions of the resting every time the user moves on to next posture. These adjustments have to be done every time and this may lead to increased dedication and devotion of time.

An online blog titled, "10 Mobile Apps Every Yogi Should Have" by Ralph Moseley [12] lists ten best applications for mobile devices. But most of the applications mentioned in this blog are IOS based and not Android based, even though Android is the most widely used mobile platform. Another list by Yoga International [13] gives evidence for this hypothesis. Adding to that the applications listed are paid, and may have monthly subscriptions which make them expensive. Only one application is open source and only three are based on Android platform.

Diamond Dallas Page (DDP) is providing yoga services on desktops and mobile devices. But according to the website of DDP [14], the services were originally developed for athletes who have suffered years of injuries due to high impact of sports. A solitary session of yoga can prompt to change in sympatho-vagal adjust (Huang et al. 2013), intellectual execution (Gothe et al. 2013), recuperation after unpleasant jolts (Sharma et al. 2007) and baroreflex affect ability, with better oxygen immersion and diminished chemoreflex affect ability (Mason et al. 2013). In spite of the fact that there gives off an impression of being a reasonable relationship amongst yoga and autonomic capacity, there is no studies which proves any considerable amount of damage during various yoga rehearses or unpleasant jolts in metabolic disorder patients. To fill this crevice, the accompanying review was intended to look at the sensors readings and distinctive yoga practices, and think about the statistical data and psycho- 
physiological reactions of standard yoga specialists, non-yoga professionals and metabolic disorder patients.

With the wearable technology growing in this technology savvy world, our ancient practice of Yoga, which is very well described in granths(books) but not many people know about it. The television has brought the asanas to the comfort of home, but rarely young and middle aged people watch them. Still the credo of these people is towards staying fit and avoiding diseases. Mobile phones, tablets, phablets, and all in one laptops are the newest technology which attracts young and middle-aged people due to its portability and multifunctionality. Sample yoga postures are highlighted in Fig 1.

Most of the industries have moved towards mobile technology.. For example shopping through online due to the advent of shopping application like Amazon, Myntra, Flipkart, Abof etc. using mobile devices. Another instance is mobile news applications. Traditionally, people used to read the written material from newspapers, books and magazines are now shifted to mobile applications like Play Newsstand, Google News and Weather, Fast News, NewsSuite, etc. Here the subscribers can read and get notifications about news updates throughout the day in real time.

Even Kamlesh Barwal, Director of Sri Sri yoga in his article named "Smart Yoga for Smartphone users"[15], accepts that mobile devices have made everybody's lives more convenient.

\subsection{Problem statement}

From the above mentioned review works we found that there is no computer based yoga monitoring system which is more economical and efficient. So the challenge is to design an engineered product which will be beneficial for the normal yoga practitioners. Our aim is to integrate the knowledge of yoga derived by yogis and ancient saints which are mentioned in granths with the latest mobile devices.

\section{Proposed system architecture}

\subsection{System hardware}

Basically, four sensors are used in this system.. The sensors are: DHT-22 (Humidity and Temperature sensor), ADXL-345 (Accelerometer) and Heart rate sensor (HRM-2511E) Arduino Nano with ATMega 328 micro-controller was used as board for connecting sensors and transmission module. A Bluetooth module (HC-05) is used to connect the kit to android phone with bluetooth module. Our prototype embedded kit is shown in Fig 2.

This figure for the kit is a prototype, the authors plan to upgrade the model with Arduino Nano which is even physically small and cheaper. The advantage of Arduino over other embedded systems includes simplicity, modularity and economic boards. Another advantage of using Arduino is faster execution of source code on the hardware. As the development of Arduino code is done on Arduino's own IDE which was developed specially for Arduino boards and there are no third party software and conversion of code, the program runs smoothly reducing chances of getting errors.

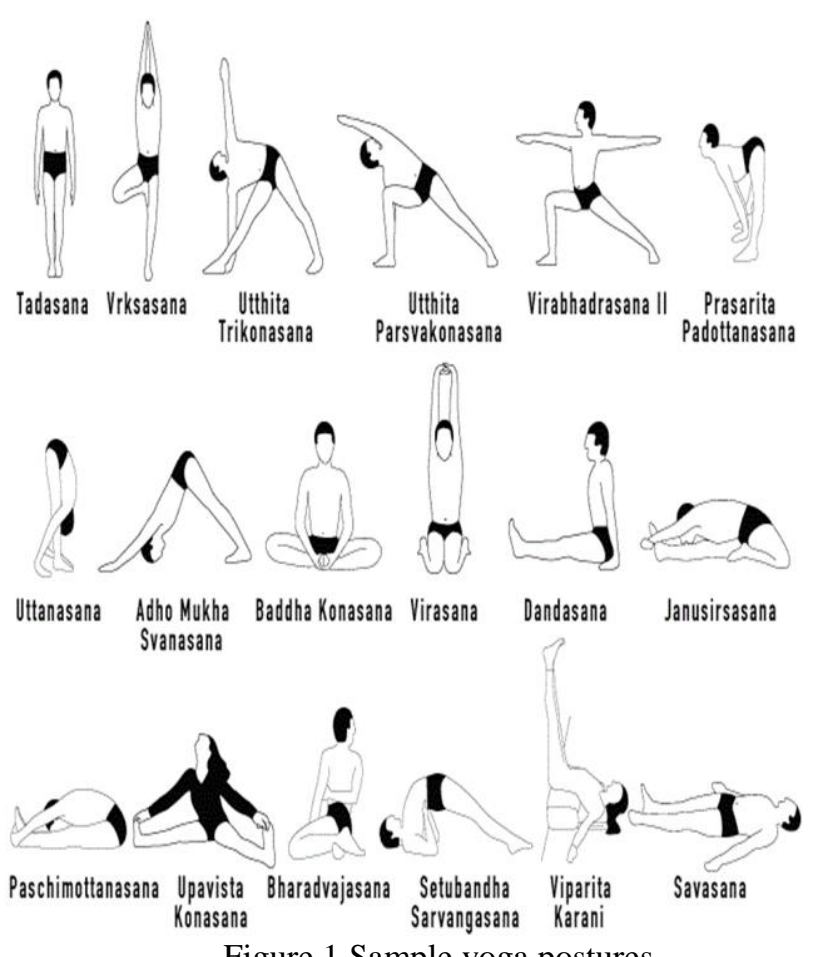

Figure.1 Sample yoga postures

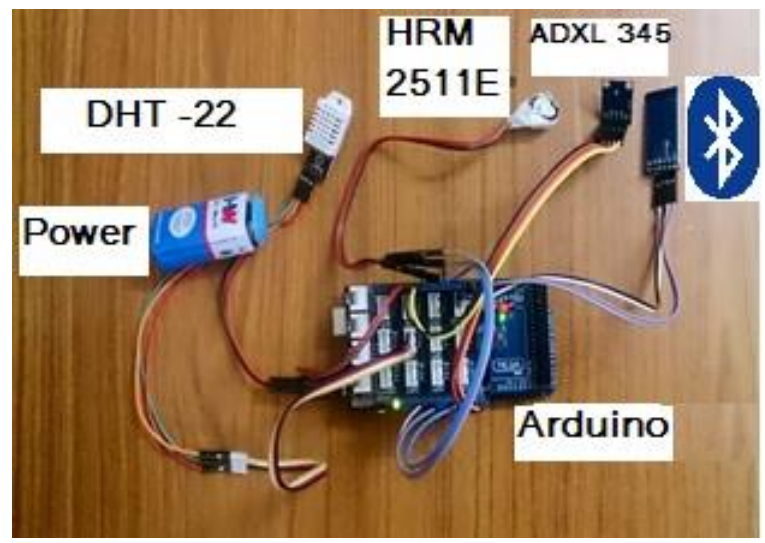

Figure.2 Prototype embedded kit 


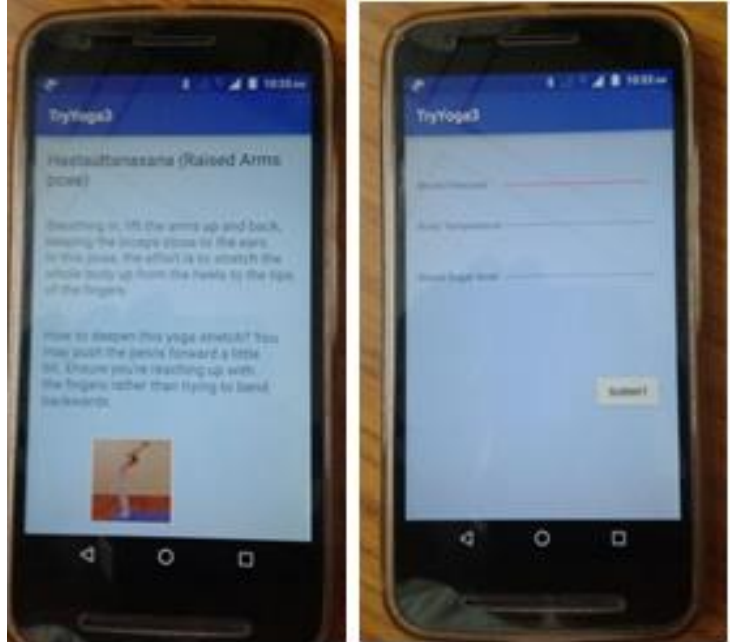

Figure.3 Android application

An android application (Refer Fig 3) was developed to receive and process the data from the developed system. The Bluetooth module can transfer and receive the data using wireless communication with ease. This allows yoga practitioners to perform postures without the hassle of connection wires from the phone. While running the application, a main page displays the option for starting the default asanas. Then a series of images and text is displayed after five seconds of postures for every asanas. Also the voice clip for text displayed in screen is played. This application provides the option for user to change the time interval.

Similarly, swiping right from left side of screen will open a side drawer box. This box contains options for history, uploading data, videos and written instructions. The history option will lead to a screen displaying graphs of user's history. The videos option will load a screen with a number of yoga videos that can be accessed. Tapping on the uploading data option will lead to a screen where the data received can be entered into the application database manually. Finally, if a user wants the read the posture instruction, the option "Written instructions" should be tapped. The application automatically creates sockets and connects to the hardware.

\subsection{System intelligence}

A system prototype was built to get sample results. The Fig.4 shows the block diagram of embedded kit. This exposure unveils frameworks, strategies, and mechanical assembly went for empowering exercise and different exercises by securing and opening usefulness a registering gadget, for example, a cell phone, portable workstation phone, a TV, to give some examples, in view of fruition of certifiable work out (e.g., running) or other genuine exercises. Different parts of this mechanism includes systems, methods, and mechanical assembly to secure and open usefulness applications running on a figuring gadget in view of culmination of true exercises.

Client movement information can be given to a processing gadget by client itself. For example, a client can physically enter client action information into a figuring gadget like a portable workstation or cell phone. Client movement information can be self-governed and measured and is inputted to a processor of a figuring gadget. For example where a client gadget both screens and bolsters from client contribution by continually sending information to the servers from the device. Thus making it less demanding for the client to gather information remotely.

A checking gadget, for example, a pedometer or module Within a portable registering device (e.g., cellphone or advanced cell), accelerometer , gyroscope, to name a couple, can be utilized to screen the client movement. By and large, the screen client action operation 104 incorporates observing physical movement or work out. For example, a pedometer can be utilized to gauge various strides taken by a client over a timeframe. Observing can be consistent or intermittent. In the case of checking client steps utilizing a pedometer, the observing might be consistent.

Once the information has been transferred, it can be contrasted with at least one edges in the contrast with threshold(s) choice. The think about choice figures out if adequate movement has been refined to empower or open a device, feature, or application.

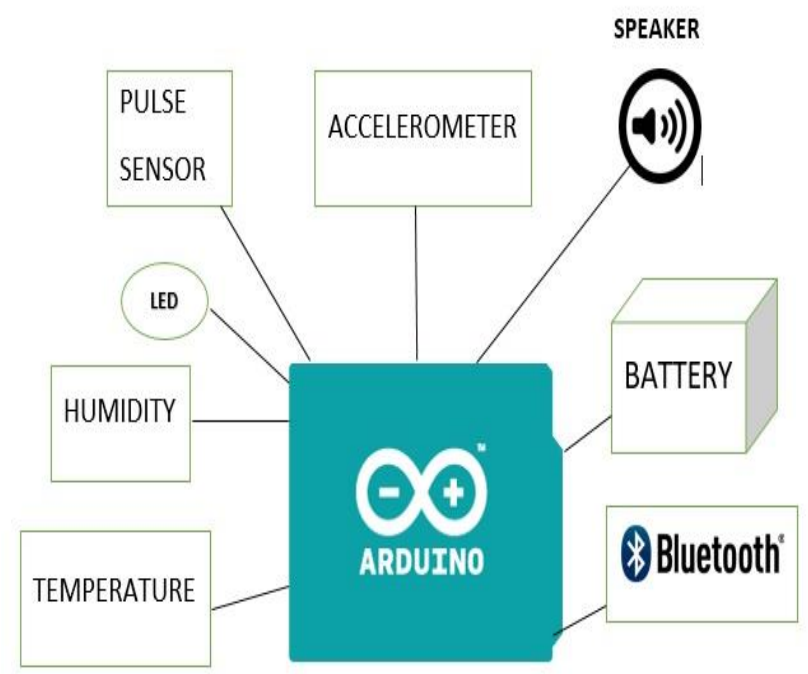

Figure.4 Block diagram of embedded kit 
For example, the contrast with threshold(s) choice may think about various accurately performed exercises amid the yoga session. As another illustration, the analyze choice may contrast various errands finished with a limit number set by an alternate individual for any given day. At the end of the day, the contrast with threshold(s) choice figures out if the client action meets a predefined objective. The client can likewise read movement information from the observing gadget and information the action information into the client gadgets. The movement information might be encoded to avoid client control of the action information.

The observing gadget can be joined to the client, for example through a belt or Waist association or a band holding the checking gadget to the client's Wrist, arm, or lower leg. The observing gadget can likewise be fabricated into, or be a part of, other gadgets, for example, a Wrist Watch, heart-rate monitor, GPS locator, cell phone, or music player.

Sun salutation comprised of 12 steps as listed in the numerical order is named as follows: Pranamasana, Hastauttanasana, Hasta Padasana, Ashwa Sanchalanasana, Dandasana, Ashtanga Namaskara,
Bhujangasana, Parvatasana, Ashwa Sanchalanasana, HastaPadasana, Hastauttanasa, and Pranama asana . These postures will energize each and every cell in the human body.It has been proven that Sun salutation steps are very useful in maintaining the heart beats, temperature and humidity and the real time data is shown in Table 1 and sample Android app screenshots are provided in Fig 5. This Data was recorded for people with following characteristics as portrayed in Table 1.

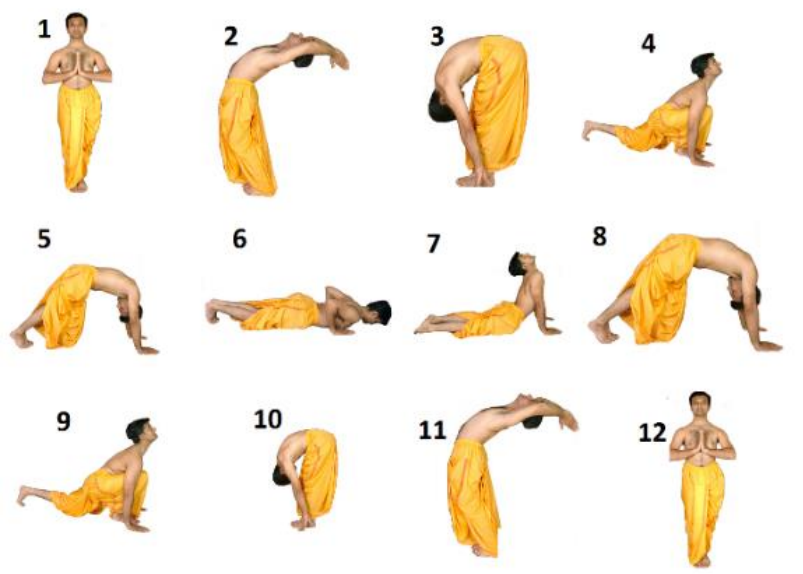

Figure.4 Block diagram of embedded kit

Table 1. Sample data collected of Age group 20-25

\begin{tabular}{|c|c|r|r|r|r|r|r|r|r|r|r|}
\hline No. & Age & Weight & Height & Sex & Rounds & HBB & HBA & TB & \multicolumn{1}{|c|}{ TA } & HB & HA \\
\hline 1 & $\mathbf{2 0}$ & $\mathbf{5 2}$ & $\mathbf{1 5 0}$ & $\mathbf{M}$ & $\mathbf{1 0}$ & $\mathbf{7 5}$ & $\mathbf{6 9}$ & $\mathbf{2 9}$ & $\mathbf{3 3}$ & $\mathbf{8 6}$ & $\mathbf{8 8}$ \\
\hline 2 & 22 & 61 & 165 & $\mathrm{M}$ & 7 & 74 & 72 & 28 & 35 & 82 & 89 \\
\hline 3 & 19 & 47 & 163 & $\mathrm{~F}$ & 9 & 79 & 80 & 33 & 34 & 91 & 88 \\
\hline 4 & 24 & 58 & 160 & $\mathrm{M}$ & 10 & 81 & 78 & 28 & 35 & 88 & 89 \\
\hline 5 & 22 & 56 & 157 & $\mathrm{M}$ & 10 & 87 & 71 & 33 & 32 & 87 & 85 \\
\hline 6 & 25 & 62 & 153 & $\mathrm{M}$ & 8 & 83 & 79 & 28 & 33 & 87 & 86 \\
\hline 7 & 21 & 70 & 165 & $\mathrm{M}$ & 6 & 81 & 76 & 29 & 34 & 85 & 86 \\
\hline 8 & 20 & 55 & 155 & $\mathrm{~F}$ & 4 & 78 & 79 & 29 & 33 & 86 & 88 \\
\hline 9 & 23 & 45 & 148 & $\mathrm{M}$ & 6 & 80 & 70 & 28 & 32 & 91 & 88 \\
\hline 10 & 25 & 63 & 170 & $\mathrm{M}$ & 6 & 73 & 71 & 29 & 32 & 83 & 86 \\
\hline 11 & 24 & 62 & 154 & $\mathrm{M}$ & 9 & 74 & 74 & 31 & 30 & 82 & 85 \\
\hline 12 & 20 & 53 & 155 & $\mathrm{M}$ & 6 & 86 & 74 & 30 & 31 & 91 & 87 \\
\hline 13 & 22 & 54 & 165 & $\mathrm{~F}$ & 6 & 82 & 75 & 30 & 29 & 89 & 86 \\
\hline 14 & 23 & 75 & 170 & $\mathrm{M}$ & 9 & 80 & 72 & 31 & 28 & 84 & 86 \\
\hline 15 & 25 & 70 & 160 & $\mathrm{M}$ & 11 & 82 & 70 & 28 & 35 & 84 & 90 \\
\hline 16 & 24 & 66 & 165 & $\mathrm{M}$ & 11 & 81 & 78 & 28 & 34 & 91 & 88 \\
\hline 17 & 21 & 55 & 160 & $\mathrm{M}$ & 10 & 76 & 69 & 34 & 33 & 82 & 85 \\
\hline
\end{tabular}

\section{System analysis \& results}

Our system is evaluated by various yoga practice persons under various age group. For better analysis we derived the BMI (Body Mass Index) of each person using Eq. (1).

$$
\mathrm{BMI}=\text { Weight }(\text { in } \mathrm{kg}) /(\text { Height in meter })^{2}
$$

Table 3 shows the BMI ranges and its equivalent health conditions. Based on the derived BMI value, we clustered each group into two as Healthy and Unhealthy persons. Healthy persons possess a BMI value between 18.5 and 24.9. The persons who possess below and above of this particular range is considered as unhealthy persons. We analyzed the data of different age group and different clusters. 
Table 2: Sample data collected of Age group 26-40

\begin{tabular}{|c|c|c|c|c|c|c|c|r|r|r|r|}
\hline No. & Age & Weight & Height & Sex & Rounds & HBB & HBA & TB & \multicolumn{1}{l|}{ TA } & HB & HA \\
\hline 1 & $\mathbf{2 7}$ & $\mathbf{7 0}$ & $\mathbf{1 6 0}$ & $\mathbf{M}$ & $\mathbf{5}$ & $\mathbf{8 1}$ & $\mathbf{7 6}$ & $\mathbf{3 1}$ & $\mathbf{3 4}$ & $\mathbf{8 7}$ & $\mathbf{8 5}$ \\
\hline 2 & 29 & 54 & 162 & F & 11 & 85 & 80 & 33 & 30 & 85 & 88 \\
\hline 3 & 30 & 69 & 172 & M & 7 & 87 & 71 & 33 & 34 & 87 & 85 \\
\hline 4 & 35 & 62 & 155 & M & 10 & 85 & 70 & 33 & 34 & 87 & 85 \\
\hline 5 & 27 & 64 & 169 & F & 7 & 81 & 80 & 32 & 35 & 87 & 85 \\
\hline 6 & 37 & 68 & 172 & M & 11 & 78 & 77 & 34 & 28 & 85 & 88 \\
\hline 7 & 33 & 50 & 150 & F & 4 & 77 & 75 & 33 & 34 & 84 & 87 \\
\hline 8 & 34 & 58 & 162 & F & 4 & 81 & 72 & 31 & 29 & 83 & 91 \\
\hline 9 & 37 & 70 & 170 & M & 5 & 80 & 79 & 29 & 30 & 89 & 88 \\
\hline 10 & 39 & 53 & 175 & M & 10 & 83 & 72 & 29 & 35 & 85 & 86 \\
\hline 11 & 40 & 78 & 165 & M & 12 & 74 & 72 & 29 & 29 & 88 & 91 \\
\hline 12 & 35 & 65 & 163 & F & 8 & 75 & 74 & 33 & 34 & 83 & 86 \\
\hline 13 & 33 & 72 & 180 & M & 10 & 85 & 75 & 30 & 33 & 88 & 88 \\
\hline 14 & 37 & 64 & 160 & F & 6 & 78 & 80 & 29 & 33 & 89 & 91 \\
\hline 15 & 38 & 71 & 163 & M & 12 & 85 & 77 & 31 & 29 & 86 & 88 \\
\hline 16 & 40 & 74 & 180 & M & 10 & 75 & 74 & 34 & 35 & 87 & 89 \\
\hline 17 & 32 & 61 & 160 & M & 7 & 75 & 78 & 34 & 35 & 86 & 89 \\
\hline 18 & 33 & 75 & 183 & M & 9 & 76 & 74 & 33 & 35 & 85 & 87 \\
\hline 19 & 35 & 67 & 172 & M & 8 & 85 & 73 & 30 & 29 & 87 & 90 \\
\hline 20 & 38 & 60 & 165 & F & 6 & 84 & 77 & 30 & 28 & 83 & 89 \\
\hline 21 & 29 & 72 & 165 & M & 5 & 80 & 70 & 28 & 35 & 86 & 87 \\
\hline 22 & 30 & 70 & 160 & M & 11 & 83 & 77 & 33 & 32 & 85 & 89 \\
\hline 23 & 38 & 55 & 155 & F & 8 & 76 & 71 & 33 & 28 & 89 & 88 \\
\hline
\end{tabular}

Table 3. BMI Status

\begin{tabular}{|c|c|}
\hline BMI range & Health condition \\
\hline BMI $<18.5$ & Under weight \\
\hline $18.6-24.9$ & Healthy \\
\hline $25-29.9$ & Over weight \\
\hline BMI $>29.9$ & Obesity \\
\hline
\end{tabular}

The data collected and much more data tables and analytical graphs are provided in our blog [23]. Fig 7 shows the analytical results of Table 1 and 2 . The analysis study shows that the parameters like heartbeat rate, body temperature and humidity is improved after using our proposed system. Heartbeat count is improvised a lot for women yoga practice person and body temperature is drastically managed for persons at the age group between 25 and 40. Blood pressure is controlled for persons above 50 years. The comparative analysis of various parameters for different age groups are illustrated in the below set of graphs. From graph analysis it is clear that our proposed system provides an enhanced support to the yoga practice persons. The comparison results between various parameters of our system and other existing system is portrayed in Table 4.

\section{Conclusions}

Yoga plays a vital role in enhancing a person mentally, physically and spiritually. Our proposed system based on integrating IoT based application with yoga helps the yoga practice person to lively monitor their physical parameters and thereby adapt themselves to perform the relevant yoga postures. The smart app processes the input data sensed by the sensors and derive suitable inferences based on the BMI (Body Mass Index) of the yoga practice person. Our results claim that our system is much beneficial for yoga practice persons as well as yoga professionals to perform yoga efficiently and effectively. Our future works may focus on remotely monitoring these sensed information by a medical practitioner or physical trainer and providing their suggestions or instructions to the yoga person as live updates.

\section{Acknowledgments}

The authors gratefully acknowledge VIT University, Vellore for the support through Seed Grant for Research. We also express our sincere gratitude towards Amrutha Yoga center for providing the necessary help. 


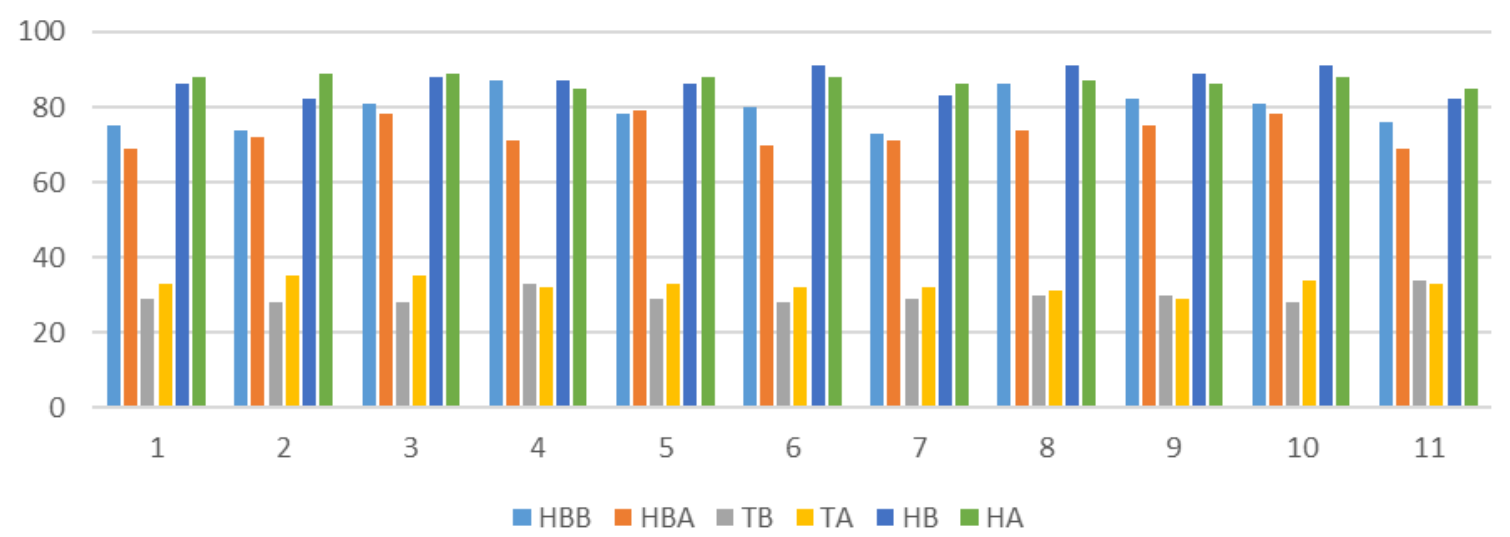

(a)

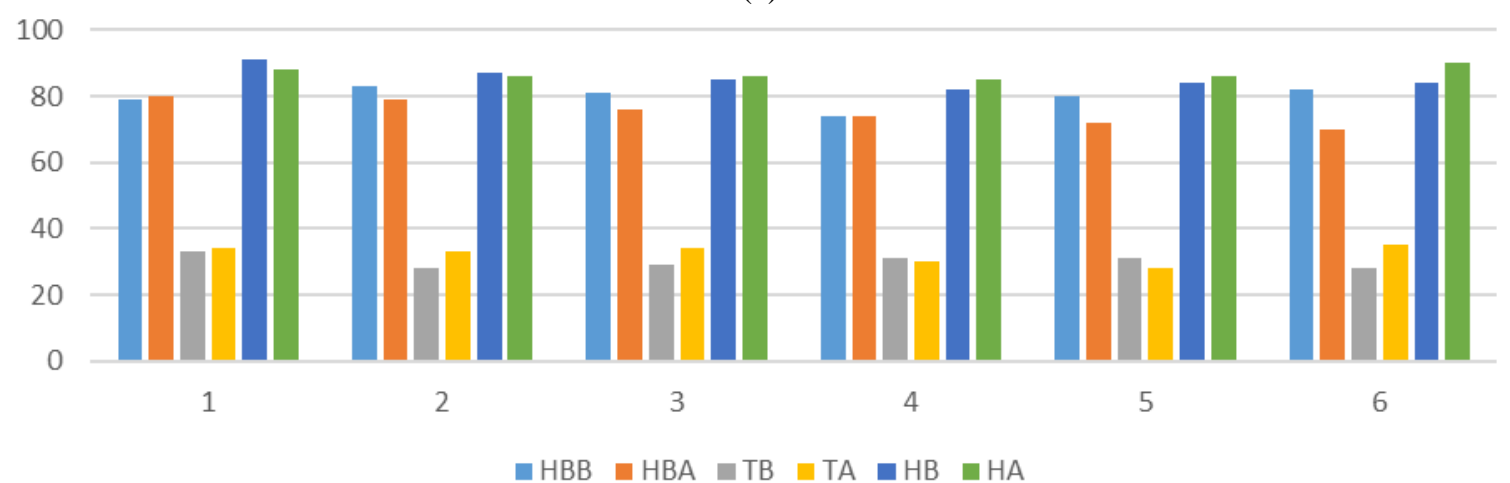

(b)

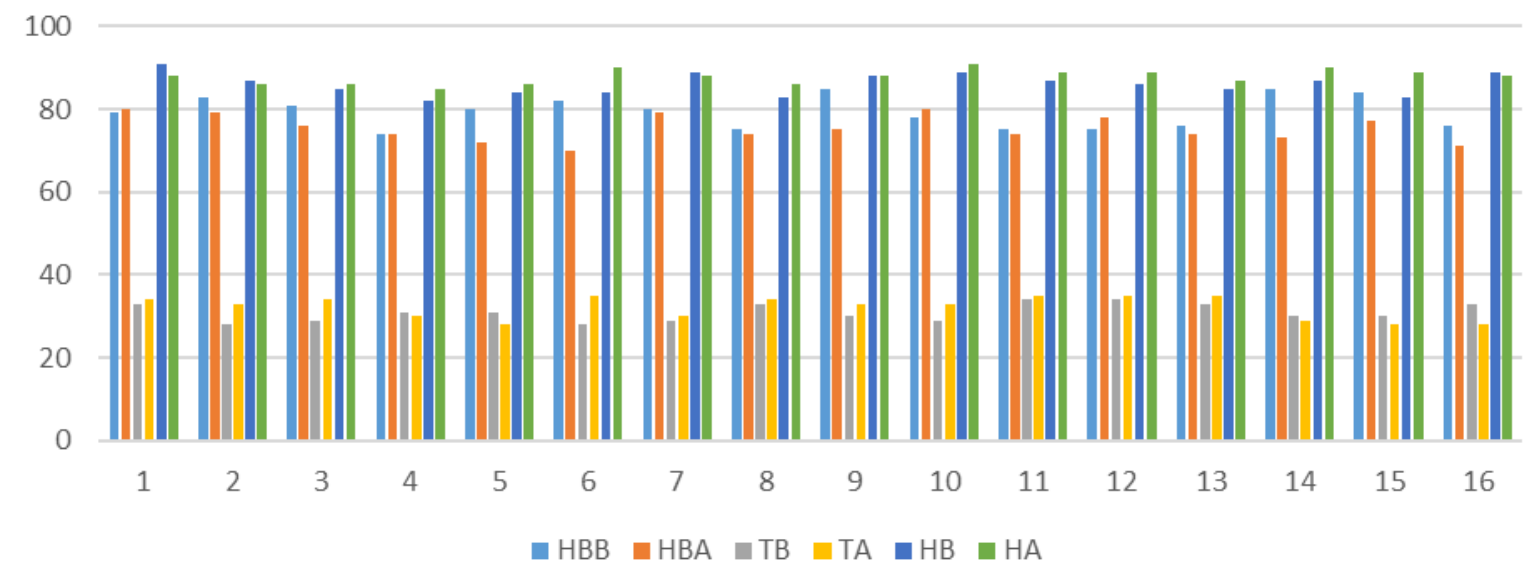

(c)

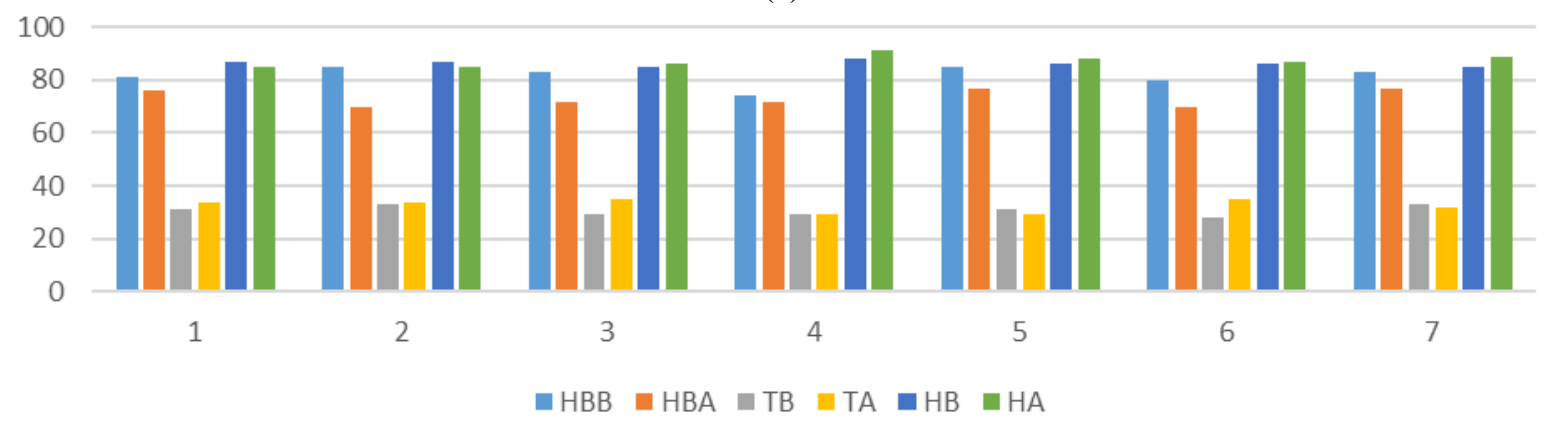

(d)

Figure.7 Analytical results: (a) Healthy person (Age between 20 and 25), (b) Unhealthy person (Age between 20 and 25), (c) Healthy person (Age between 26 and 40), and (d) Unhealthy person (Age between 26 and 40) 
Table 4. Comparison of various parameters

\begin{tabular}{|c|c|c|}
\hline \multicolumn{3}{|r|}{ 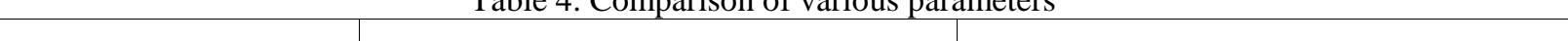 } \\
\hline Parameters & Hardware Kit Developed & Existing Hardware Available \\
\hline Features & $\begin{array}{l}\text { Reliable, Durable, Robust, Tangible, } \\
\text { Accurate. }\end{array}$ & $\begin{array}{l}\text { Stable but requires more power and } \\
\text { amateurish. }\end{array}$ \\
\hline Cost & $\begin{array}{l}\text { Economical and Ergonomic in terms of } \\
\text { usage. }\end{array}$ & $\begin{array}{l}\text { Costly as expensive sensor are plugged to } \\
\text { power the hardware }\end{array}$ \\
\hline Weight & $\begin{array}{l}\text { Weight of the hardware developed is very } \\
\text { less as we are using Arduino nano. }\end{array}$ & $\begin{array}{l}\text { Weight of the existing hardware is more as } \\
\text { bigger }\end{array}$ \\
\hline Connectivity & $\begin{array}{l}\text { There were no connectivity issues } \\
\text { encountered as the hardware used is } \\
\text { recently introduced in the market. }\end{array}$ & $\begin{array}{l}\text { There were connectivity issues } \\
\text { encountered during testing and } \\
\text { development as mentioned in various } \\
\text { research papers before. }\end{array}$ \\
\hline Power Consumption & $\begin{array}{l}\text { Power consumption is low as it is newly } \\
\text { developed and more enduring. It can also } \\
\text { be powered by multiple power sources }\end{array}$ & $\begin{array}{l}\text { Power consumption was more due to } \\
\text { complex circuit as mentioned in various } \\
\text { paper. }\end{array}$ \\
\hline Size & Compact and portable. & Large and bulky. \\
\hline Data Transfer & $\begin{array}{l}\text { Data transfer is faster and smoother as the } \\
\text { latest and fastest processor is used. }\end{array}$ & $\begin{array}{l}\text { Data transfer is rather slow due to low } \\
\text { older processor. }\end{array}$ \\
\hline Speed & $\begin{array}{l}\text { Speed is extensively increased to support } \\
\text { multiple devices at the same time. }\end{array}$ & $\begin{array}{l}\text { Speed was quite slow when used to support } \\
\text { multiple devices. }\end{array}$ \\
\hline Usability & $\begin{array}{l}\text { Can be easily used to support multiple } \\
\text { devices from different domains without } \\
\text { compromising speed and reliability of the } \\
\text { data transferred. }\end{array}$ & $\begin{array}{l}\text { Data was compromised when used with } \\
\text { multiple devices as support for multiple } \\
\text { devices was not suited. Mainly build as } \\
\text { single purpose. }\end{array}$ \\
\hline Example: & $\begin{array}{l}\text { Arduino powered kit, ATtiny powered } \\
\text { kit. }\end{array}$ & $\begin{array}{l}\text { Smart watch, smart band, raspberry pi } \\
\text { powered kit etc. }\end{array}$ \\
\hline
\end{tabular}

\section{References}

[1] S.J. Wu and A. Green, A Projection of Chronic Illness Prevalence and Cost Inflation, RAND Health, Santa Monica, Calif, USA, 2000.

[2] K.E. Innes, C. Bourguignon, and A.G. Taylor, "Risk Indices Associated with the Insulin Resistance Syndrome, Cardiovascular Disease, and Possible Protection with Yoga: a Systematic Review", Journal of the American Board of Family Practice, Vol. 18, No. 6, pp.491-519, 2005.

[3] K.E. Innes and H.K. Vincent, "The Influence of Yoga-Based Programs on Risk Profiles in Adults with Type 2 Diabetes Mellitus: a Systematic Review", Evidence-Based Complementary and
Alternative Medicine, Vol. 4, No. 4, pp.469-486, 2007.

[4] J.A. Raub, "Psychophysiologic Effects of Hatha Yoga on Musculoskeletal and Cardiopulmonary Function: a Literature Review", Journal of Alternative and Complementary Medicine, Vol. 8, No. 6, pp.797-812, 2002.

[5] K. Smith, B. Pukall, and F. Caroline, "An Evidence-Based Review of Yoga as a Complementary Intervention for Patients with Cancer", Psycho-Oncology, Vol. 18, No. 4, pp. 465-475, 2009.

[6] D. Vancampfort, K. Vansteeland, T. Scheewe, M. Probst, J. Knapen, A. De Herdt, and M. De Hert, "Yoga in Schizophrenia: a Systematic Review of Randomised Controlled Trials", Acta 
Psychiatrica Scandinavica, Vol.126, No.1, pp.12-20, 2012.

[7] E. Sovová, V. Čajka, D. Pastucha, J. Malinčíková, L. Radová, and M. Sovová, "Positive effect of yoga on cardiorespiratory fitness: A pilot study", Int. J. Yoga, Vol. 8, No. 2, pp. 134-138, 2015.

[8] A.R. Kristal, A.J. Littman, D. Benitez, and E. White, "Yoga Practice is Associated with Attenuated Weight Gain in Healthy, MiddleAged Men and Women," Alternative Therapies in Health and Medicine, Vol. 11, No. 4, pp.2833, 2005.

[9] N. Moliveretal, "Increased Hatha Yoga Experience Predicts Lower Body Mass Index and Reduced Medication Use in Women Over 45 Years," International Journal of Yoga, Vol. 4, pp.77-86, 2011.

[10] A. Palasuwan, I. Margaritis, S. Soogarun, and A.S. Rousseau, "Dietary Intakes and Antioxidant Status in Mind-Body Exercising Pre-and Postmenopausal Women", Journal of Nutrition, Health and Aging, Vol. 15, No. 7, pp.577-584, 2011.

[11] H. Cramer, J. Langhorst, G. Dobos, and R. Lauche, "Yoga for Metabolic Syndrome: A Systematic Review and Meta-Analysis", European Journal of Preventive Cardiology, Vol.23, No.18, pp.1982-1993, 2016.

[12] R. Moseley, "10 Mobile Apps Every Yogi Should Have", Downloaded on 23rd December, 2016 from

http://www.yogalondon.net/monkey/10mobile-apps-every-yogi-should-have/

[13] Yoga International, "Yoga and Meditation Apps for Your Smartphone or Tablet", Available at: https://yogainternational.com/article/view/yoga -and-meditation-apps-for-your-smartphone-ortablet Accessed on 12/12/2016

[14] D. Page, "About DDP", retrived on 23rd December, 2016 from https://ddpyoga.com/pages/ddp-yoga-nowcomes-to-your-mobile-devices-and-desktop-pc

[15] K. Barwal, "Smart Yoga for Smartphone Users", downloaded on 23rd December, 2016 from

http://www.artofliving.org/in-en/yoga/yogabenefits/yoga-mobile-phones

[16] S. Fels, J. Gauthier and P. Smith, "Responses in Light, Sound and Scent-A Therapeutic Interactive Yoga System", In: Proc. of the First International Workshop on Entertainment Computing, 2002.
[17] Available at: http://www.biocontrol.com, Accessed on 02/10.2016

[18] S.S. Fels, D. Reiners, and K. Mase, "Iamascope: An Interactive Kaleidoscope", Virtual Proceedings of SIGGRAPH97: The Electric Garden, pp. 76-77, 1997.

[19] J. Borchers and M. Mühlhäuser, "Musical Design Patterns: An Example of a HumanCentered Model of Interactive Multimedia", In: Proc. of the IEEE ICMCS'97 International Conference on Multimedia Computing and Systems, pp. 63-70, 1997.

[20] H. Taeger and T. Siegfried, "Manjushri Mandala retrived on 25th December, 2016 from http://www.iol.ie/'taeger/

[21] K.A. Millsap and N.J. Millsap, U.S. Patent Application No. 13/927,041, 2013.

[22] Figure retrieved from: http://siriusdisclosure.com/wpcontent/uploa ds/2012/12/Intro-to-Asanas.gif

[23] Available at http://yogadata.blogspot.com 